
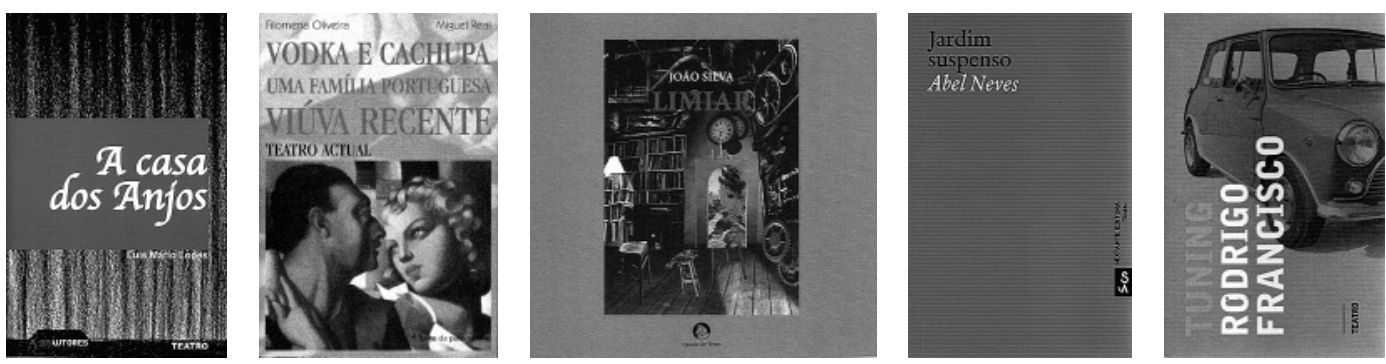

\title{
Publicações de teatro em 2010
}

\section{Lista compilada por Sebastiana Fadda}

\section{Peças originais (ou volumes de peças) em primeira edição}

AA.W., Panos: Palcos novos, palavras novas (Apanhabolas, de Rui Cardoso Martins; Belavista, de Lisa McGee, trad. Alexandra Barreto; Cenofobia, de André e. Teodósio [Teatro Praga]), Lisboa, Fundação Caixa Geral de Depósitos / Culturgest, 2010.

AA.W., Teatro português do século XVI. I. Tomo II (Auto das capelas / Auto de D. Fernando / Auto dos Enanos / Farsa penada / Auto dos Sátiros), introd. e ed. José Camões, Lisboa, Imprensa Nacional-Casa da Moeda, Biblioteca de Autores Portugueses, 2010.

ANDRÉ, João Maria, Peregrinações. Quadros inspirados em Peregrinação de Fernão Mendes Pinto adaptados e reescritos por João Maria André, Coimbra, Imprensa da Universidade de Coimbra / Câmara Municipal de Montemor-o-Velho, 2010.

CASTRO, Paulo Alexandre e, Aqui entre nós, Porto, Papiro Editora, Teatro, 2010.

FERREIRA, Cândido Gonzalez, 0 segredo de Conceição, pref. Jorge Silva Melo, Lisboa, Dinossauro Edições, 2010.

FRANCISCO, Rodrigo, Tuning, s.I. [Viana do Castelo], Livros de Areia, 2010.

GUEDES, Castro, Passarox, pref. de Fernando Dacosta e do autor, Santa Maria da Feira, Letras \&t Coisas, Colecção Teatro/01, 2010.

GUEDES, Maria Estela, Tango Sebastião, Lisboa, Apenas Livros, Teatro no Cordel n. $10,2010$.

JUNQUEIRO, Guerra, Pátria, pref. António Cândido Franco Lisboa, Nova Vega, Mnésis - Clássicos da Literatura Portuguesa, 2010.

KELLERMAN, Paulo, Chega de fado, Porto, Deriva Editora, 2010.

LOBO, Fernando, Margens da Rua Augusta \&t O unicórnio Iusitano, Lisboa, Fonte da Palavra, Teatro, 2010.

LOPES, Luís Mário, A casa dos Anjos, Lisboa, SPA, 2010.

MENDES, José Maria Vieira, Hedda, Lisboa, Artistas Unidos / Livros Cotovia, Livrinhos de Teatro n. ${ }^{\circ} 47,2010$.

MOUTINHO, José Viale, A noite de Ravensbrück. Ensaio dramático. Peças em três quadros, Porto, Edições Afrontamento, 2010.

MURRAÇAS, André, Film noir, Lisboa, Teatro Nacional D. Maria II / Bicho do Mato, 2010.
NEVES, Abel, Jardim suspenso, Lisboa / Porto, Instituto Camões / Sextante Editora, Teatro, 2010.

OLIVEIRA, Filomena / REAL, Miguel, Vodka e cachupa / Uma familia portuguesa /Viúva recente. Teatro actual, pref. dos autores, Lisboa, Fonte da Palavra, 2010.

PESSOA, Carlos J., Snapshots, Lisboa, Teatro Nacional D. Maria II / Bicho do Mato, 2010.

PIRES, Jacinto Lucas, Sagrada família, Lisboa, Livros Cotovia, Teatro, 2010.

PORTELA, Patrícia, Robinson Crusoé, Lisboa, Teatro Nacional D. Maria II / Bicho do Mato, 2010.

SAMPAIO, Jaime Salazar, Teatro completo (vol. V), introd. e org. Sebastiana Fadda, Lisboa, Imprensa NacionalCasa da Moeda, Biblioteca de Autores Portugueses, 2010.

SILVA, João, Limiar, Lisboa, Cavalo de Ferro, 2010.

TORRADO, António, 0 recepcionista e outras peças para café-teatro, Coimbra, Calendário, 2010.

--, Gaby, a princesa, prólogo do autor, Louvada, Jangada Teatro, 2010.

\section{Peças originais em reedição}

FRANCISCO, Rodrigo, Quarto minguante, s.I. [Viana do Castelo], Livros de Areia, 2010, 2a ed.

TORRAD0, António, Teatro às três pancadas (7 pequenas peças para pequenos elencos), Lisboa, Editorial Caminho, 2010, 2a ed. 


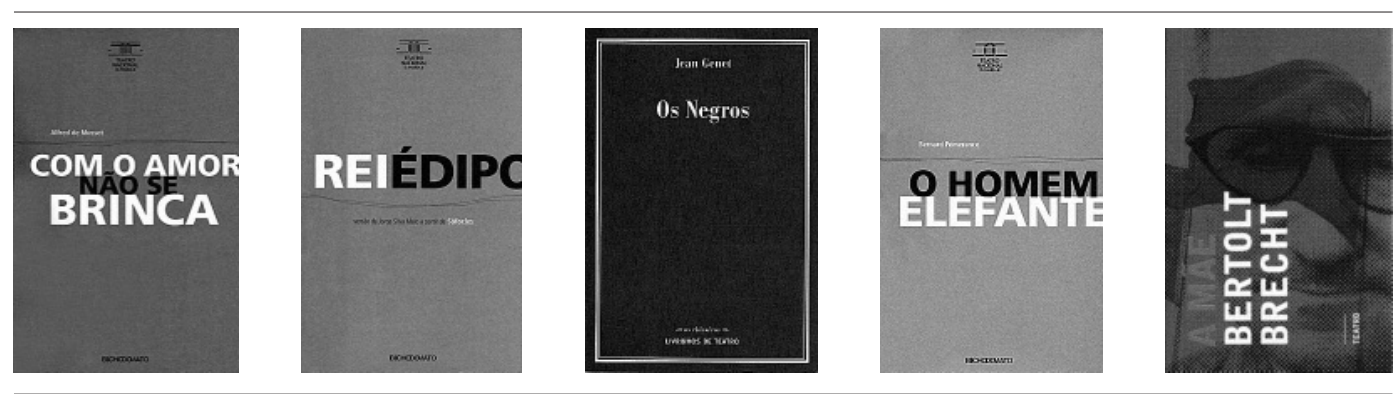

\section{Traduções}

ARISTÓFANES, Comédias (vol. II: As vespas / Paz / As aves / Lisistrata), introd., trad. e notas de Maria de Fátima Sousa e Silva e Carlos Martins de Jesus, Lisboa, Imprensa Nacional-Casa da Moeda, Biblioteca de Autores Clássicos, 2010.

BARKER, Howard, Os europeus / Lutas para amar, trad. Francisco Frazão, Ribeirão / Porto, Húmus / Teatro Nacional São João, 2010.

BRECHT, Bertolt, A mãe, trad. Yvette K. Centeno e Teresa Balté, s.l. [Viana do Castelo], Livros de Areia, 2010.

BÜCHNER, Georg, Woyzeck, trad. e pref. João Barrento, Porto, Húmus - Teatro Nacional São João, Colecção Teatro Nacional São João, 2010.

COPI, As quatro gémeas / A noite da dona Luciana / Uma visita inoportuna, trad. António Barahona, Isabel Albes e Olinda Gil, Lisboa, Artistas Unidos / Livros Cotovia, Livrinhos de Teatro n. ${ }^{\circ}$ 49, 2010.

CROUCH, Tim, $O$ autor, trad. Francisco Frazão, Lisboa, Artistas Unidos / Livros Cotovia, Livrinhos de Teatro n. ${ }^{\circ}$ 51, 2010.

CUNILLÉ, Lluisa, Barcelona, Mapa de sombras après moi, Le déluge, trad. Ângelo Ferreira de Sousa, Lisboa, Artistas Unidos / Livros Cotovia, Livrinhos de Teatro n. ${ }^{\circ}$ 43, 2010.

GENET, Jean, As criadas / Alta vigilância, trad. Luiza Neto Jorge e Jorge Silva Melo, Lisboa, Artistas Unidos / Livros Cotovia, Livrinhos de Teatro n. ${ }^{\circ}$ 42, Os Clássicos, 2010.

--, A varanda, trad. Armando Silva Carvalho, Lisboa, Artistas Unidos / Livros Cotovia, Livrinhos de Teatro n. ${ }^{0}$ 46, Os Clássicos, 2010.

--, Os negros, trad. Armando Silva Carvalho, Lisboa, Artistas Unidos / Livros Cotovia, Livrinhos de Teatro n. ${ }^{\circ}$ 50, Os Clássicos, 2010.

GREIG, David, Cantigas de uma noite de Verão (uma peça de amores e desamores) e outras peças, trad. Pedro Marques, Lisboa, Artistas Unidos / Livros Cotovia, Livrinhos de Teatro n. ${ }^{\circ}$ 41, 2010.

HARROWER, David, Blackbird, trad. Tiago Guedes, Lisboa, Teatro Nacional D. Maria II / Bicho do Mato, 2010.

KLEIST, Heinrich Von, O príncipe de Homburgo, trad. e posfácio de Luisa Costa Gomes, revisão da trad. Teresa Seruya, Lisboa, Ática, Teatro, 2010.
KOLVENBACH, John, Num dia igual aos outros, trad. Gonçalo Waddington, Marco Martins, Miguel Castro Caldas e Nuno Lopes, Lisboa, Teatro Nacional D. Maria II / Bicho do Mato, 2010.

LESAGE, Alain-René, Turcadet. Comédia em cinco actos e em prosa, trad. Luís Vasco, revisão da trad. Magda Bigotte de Figueiredo, Lisboa, Teatro Nacional D. Maria II / Bicho do Mato, 2010.

LIDDELL, Angélica, Cão morto em tinturaria: os fortes e outras peças, trad. Joana Frazão e Raquel Marques, Lisboa, Artistas Unidos / Livros Cotovia, Livrinhos de Teatro n. ${ }^{\circ} 44,2010$.

MUSSET, Alfred De, Com o amor não se brinca, trad. Magda Bigotte de Figueiredo, Lisboa, Teatro Nacional D. Maria II / Bicho do Mato, 2010.

POMERANCE, Bernard, O homem elefante, trad. e epilogo de Miguel Castro Caldas, Lisboa, Teatro Nacional D. Maria II / Bicho do Mato, 2010.

PUJOL, Susana, Delfina. Uma paixão, introd., estudo e trad. Ana Maria da Costa Toscano, Porto, Universidade Fernando Pessoa, 2010.

SÓFOCLES, Rei Édipo, versão de Jorge Silva Melo, Lisboa, Teatro Nacional D. Maria II / Bicho do Mato, 2010.

STEPHENS, Simon, Um precipicio no mar / Punk rock, trad. Hélia Correia e Joana Frazão, Lisboa, Artistas Unidos / Livros Cotovia, Livrinhos de Teatro n. ${ }^{\circ}$ 45, 2010.

STOPPARD, Tom, Agora a sério, trad. Pedro Mexia, Lisboa, Tinta da China, 2010.

VALENTIN, Karl, A fanfarra e outros textos, trad. Luiza Neto Jorge, Maria Adélia Silva Melo, Osório Mateus e Almeida Faria, Lisboa, Artistas Unidos / Livros Cotovia, Livrinhos de Teatro n. ${ }^{\circ}$ 48, Os Clássicos, 2010.

WILDE, Oscar, Uma mulher sem importância, trad. Carla Morais Pires, revisão da trad. Gualter Cunha, Lisboa, Ática, Teatro, 2010. 


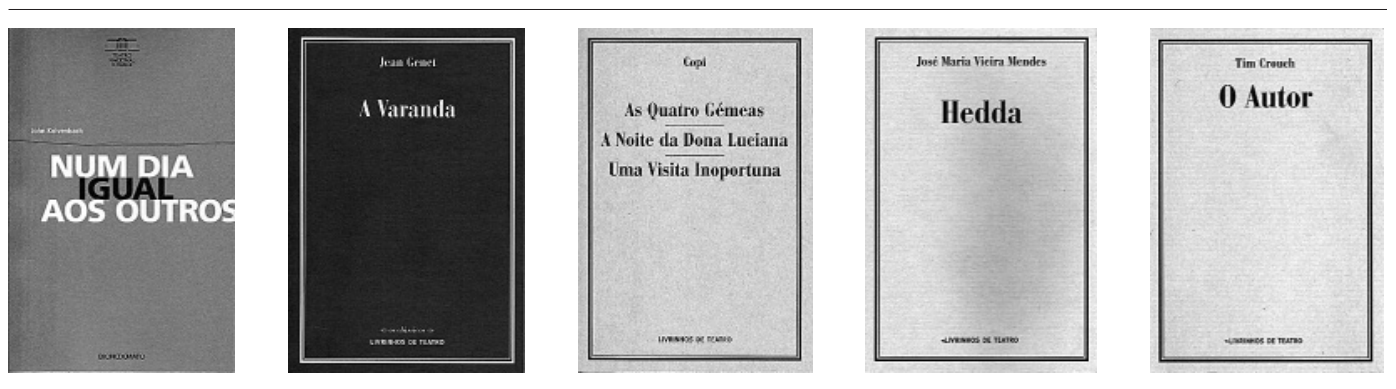

\section{Traduções em reedição}

BECKETT, Samuel, Dias felizes, trad. Jaime Salazar Sampaio, Lisboa, Editorial Estampa, 2010, 4a ed.

ÉSQUILO, Agamemnon, Coeforas, Euménides, tradução, introdução e notas de Manuel de Oliveira Pulquério, Lisboa, Edições 70, Clássicos Gregos e Latinos, 2010 $6^{a}$ ed.

SÓFOCLES, Rei Édipo, tradução, introdução e notas de Maria do Céu Zambujo Fialho, Lisboa, Edições 70, Clássicos Gregos e Latinos, 2010, 7ª ed.

\section{Estudos / Documentos}

AA.W., A República das artes: Teatro (Teatro: A República do teatro (1900-1926), por Maria Helena Serôdio; As músicas da República Il: O ensino vocacional da música: uma miragem impossivel, por Rui Vieira Nery; Alexandre Rey Colaço (1854-1928): sentimento mediterrânico e disciplina germânica, por Rui Vieira Nery; CD Alexandre Rey Colaço: Fados para piano, com Afonso Malão ao piano), Lisboa, Tugaland Edições Multimédia, Centenário da República Portuguesa 1910-2010, 2010.

ADAMOPOULOS, Sarah, Nicolau Breyner: É melhor ser alegre do que ser triste, Lisboa, Planeta, 2010.

ANDRÉ, Teresa, António Pedro e o teatro em Portugal, prefácios de Luiz Francisco Rebello, Júlio Gago e Eugénia Vasques, Lisboa, s.e. [edição da autora], 2010.

BORGES, Gabriela (org), Nas margens: Ensaios sobre teatro, cinema e meios digitais, Lisboa, Editora Gradiva, Colecção Arte e Media, 2010.

BRANCO, Salwa Castelo (dir.), Enciclopédia da música em Portugal no século XX (vol.2: C-L; vol. 3: L-P), Lisboa, Temas \& Debates, 2010.

CARNEIRO, Luis Soares, A estranheza da Estipite / The Strangness of the Estipite. Marques da Silva e o(s) Teatro(s) de S. João / Marques da Silva and the S. João Theatre(s), trad. Anthony Kinnon, Porto, Fundação Instituto Arquitecto José Marques da Silva, 2010.

CASTRO, Vera, 0 papel da segunda pele, Lisboa, Athena, 2010.

DANAN, Joseph, 0 que é a dramaturgia?, trad. Luis Varela Évora, Editora Licorne, Teatro-Materiais 1, 2010.

FEIO, António, Aproveitem a vida. Não deixem nada por fazer, nem nada por dizer, colaboração de Maria João Costa, Lisboa, D. Quixote, Livros d'Hoje, 2010.
FLORINDO, João M. A., Ester Leão: Uma actriz na República Gavião, Ramiro Leão, 2010

MACEDO, Ana Gabriela et al. (org.), Estudos performativos: Global Performance, Political Performance, V. Nova de Famalicão, Húmus, 2010.

MOLINARI, Cesare, História do teatro, trad. Sandra Escobar Lisboa, Edições 70, Arte e Comunicação, 2010.

MONTEIRO, Paulo Filipe, Drama e comunicação, Coimbra, Imprensa da Universidade de Coimbra, 2010.

MORAIS, Carlos, 0 trímetro sofocliano: variações sobre um esquema, pref. Maria Helena da Rocha Pereira, Lisboa Fundação Calouste Gulbenkian / Fundação para a Ciência e a Tecnologia, Ministério da Ciência, Tecnologia e Ensino Superior, Textos Universitários de Ciências Sociais e Humanas, 2010.

NAVARRO, António Rebordão, Júlio Cardoso no palco do vida: 50 anos de teatro, Porto, Seiva Trupe - Teatro Vivo, 2010

RANCIĖRE, Jacques, 0 espectador emancipado, trad. José Miranda Justo, Lisboa, Orfeu Negro, 2010.

REBELLO, Luiz Francisco, Três espelhos. Uma visão panorâmica do teatro português do liberalismo à ditadura (1820-1926), Lisboa, Imprensa NacionalCasa da Moeda, Colecção Temas Portugueses, 2010.

REIS, Luciano, 0 grande livro do espectáculo. Personalidades artísticas. Séc. $X X$, vol. I, pref. Duarte Ivo Cruz, Lisboa Fonte da Palvra, 2010.

ROCHA, Luzia, Opera \&t caricatura. 0 Teatro de São Carlos na obra de Rafael Bordalo Pinheiro (vol. I e vol. II), Lisboa, Edições Colibri / Centro de Estudos de Sociologia e Estética Musical da Universidade Nova de Lisboa, Colecção Estudos Musicológicos, 2010

SCHIAPPA, Bruno, Fernando Arrabal: 0 paradoxo da teatralidade, Lisboa, Coisas de Ler, 2010.

VALVERDE, Isabel Maria de Cavadas, Interfaces dançatecnologia: um quadro teórico para a performance no domínio digital, Lisboa, Fundação Calouste Gulbenkian / Fundação para a Ciência e a Tecnologia, Ministério da Ciência, Tecnologia e Ensino Superior, Textos Universitários de Ciências Sociais e Humanas, 2010.

VASQUES, Eugénia, Para a história da encenação em Portugal: 0 difícil progresso do conceito de encenação no teatro, Lisboa, Sá da Costa Editora, 2010. 

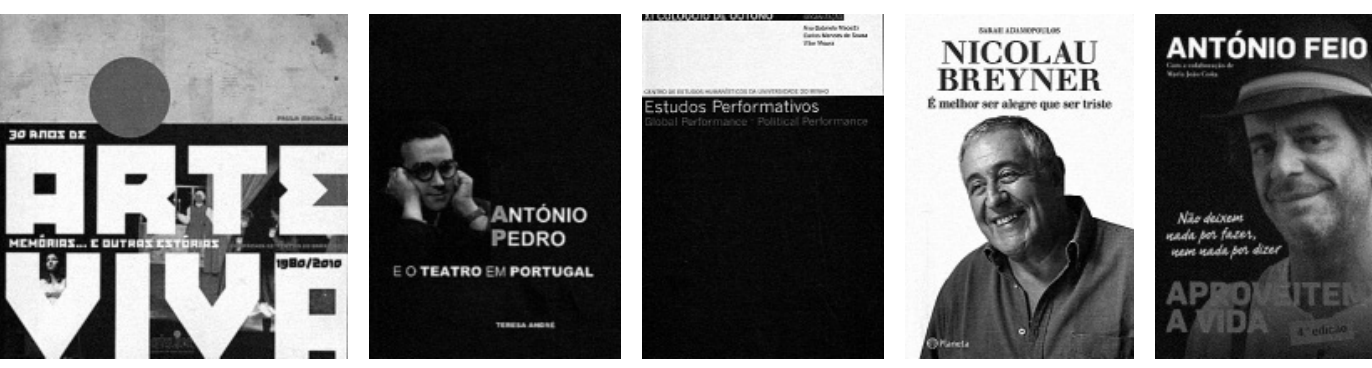

VAZ, Henrique Malheiro, Prospecto Zero. A escola do teatro. Significado da instância de trabalho numa escola profissional artística: estudo de caso, pref. José Alberto Correia, Lisboa, Fundação Calouste Gulbenkian / Fundação para a Ciência e a Tecnologia, Ministério da Ciência, Tecnologia e Ensino Superior, Textos Universitários de Ciências Sociais e Humanas, 2010.

\section{Publicações periódicas}

Cine Qua Non: Bilingual Arts Magazine | music dance theatre visual arts literature cinema, n. ${ }^{\circ} 2$ (Winter 2010) e 3 (Summer/Fall), dir. Ana Luisa Valdeira da Silva, Lisboa, Centro de Estudos Anglisticos da Universidade de Lisboa.

Obscena: Revista de artes performativas, n's 23 (Maio/Junho 2010), e 24 (Julho/Agosto 2010), dir. Tiago Bartolomeu Costa, Lisboa.

Sinais de cena, nº 13 (Junho 2010) e 14 (Dezembro 2010), dir. Maria Helena Serôdio, Lisboa, Associação Portuguesa de Críticos de Teatro \&t Centro de Estudos de Teatro, Húmus.

\section{Adenda à lista publicada na Sinais de cena n. ${ }^{\circ} 13$ (2009)}

ALLEN, Woody, Infidelidades. Três peças em um acto, trad. e notas de Helena Briga Nogueira e José Miguel Silva, Lisboa, Relógio d'Água, 2009. [tradução]

ARISTÓFANES, As rãs, tradução, introdução e notas de Américo da Costa Ramalho, Lisboa, Edições 70, Clássicos Gregos e Latinos, 2009. [tradução]

Artistas Unidos: Revista, n. 24 (Dezembro 2009), dir. Jorge Silva Melo, Lisboa, Livros Cotovia. [publicação periódica]

CORREIA, Natália. O progresso de Édipo. Poema dramático, ed. e pref. Armando Nascimento Rosa, Amadora, CIAC/Escola Superior de Teatro e Cinema, 2009. [peça original]

--, O mistério da cidade de Hic-Hec-Hoc, Coimbra, Calendário, 2008. [peça original]

--, 0 adorável homem das neves (mágica em 2 actos), Lisboa, Editorial Caminho, 2008, 5 a ed. [peça original em reedição]
--, O homem sem sombra, Lisboa, Editorial Caminho, 2008, $2^{\mathrm{a}}$ ed. [peça original em reedição]

--, Toca e foge ou A flauta sem mágica (em 2 actos), Lisboa, Editorial Caminho, 2008, 2a ed. [peça original em reedição]

ÉSQUILO, Persas, tradução, introdução e notas de Manuel de Oliveira Pulquério, Lisboa, Edições 70, Clássicos Gregos e Latinos, 2009, $3^{\mathrm{a}}$ ed. [tradução em reedição]

ROSA, Armando Nascimento, Não és Beckett não és nada ou Espera apócrifa reloaded. Uma paródia beckettiana, Lisboa, Apenas Livros, Teatro no Cordel n. 9 2009. [peça original]

Setepalcos, n. 6 (Dezembro 2009), dir. António Augusto Barros, Coimbra. [publicação periódica]

TORRADO, António, Os Maias no Trindade, Lisboa, Fundação INATEL, 2009. [peça original]

--, Romeu loves Julieta, Viana do Castelo, Câmara Municipal de Viana do Castelo - Biblioteca, 2009 [peça original]

VÁRZEAS, Maria Isabel de Oliveira, A força da palavra no teatro de Sófocles: Entre retórica e política, Lisboa, Fundação Calouste Gulbenkian / Fundação para a Ciência e a Tecnologia, Ministério da Ciência, Tecnologia e Ensino Superior, Textos Universitários de Ciências Sociais e Humanas, 2009. [estudos / documentos]

\section{Adenda à lista publicada na Sinais de cena n. ${ }^{\circ} 11$ (2008)}

BERNARDES, José Augusto Cardoso, Gil Vicente, Lisboa, Edições 70, Colecção Cânone, 2008. [estudos / documentos]

BERNARDO, Firmino, Memórias de uma vida para esquecer pref. Mário de Carvalho, Lisboa, Apenas Livros, Teatro no Cordel n. ${ }^{\circ} 8,2008$. [peça original]

NORAS, José Augusto, Cenas da Vida de um Cine-Teatro: - Teatro Rosa Damasceno de Santarém, Lisboa, Apenas Livros, 2008. [estudos / documentos]

RAMOS, Ana Margarida / RECHOU, Blanca-Ana Roig / GOMES, José António (coord.), Teatro para infância e juventude. Aproximações à literatura dramática, s.l. [Porto], Deriva, 2008. [estudos / documentos]

SILVA, Sara Reis da / RODRIGUEZ, Marta Neira, Do livro à cena, s.l. [Porto ], Deriva, 2008. [estudos/documentos] 

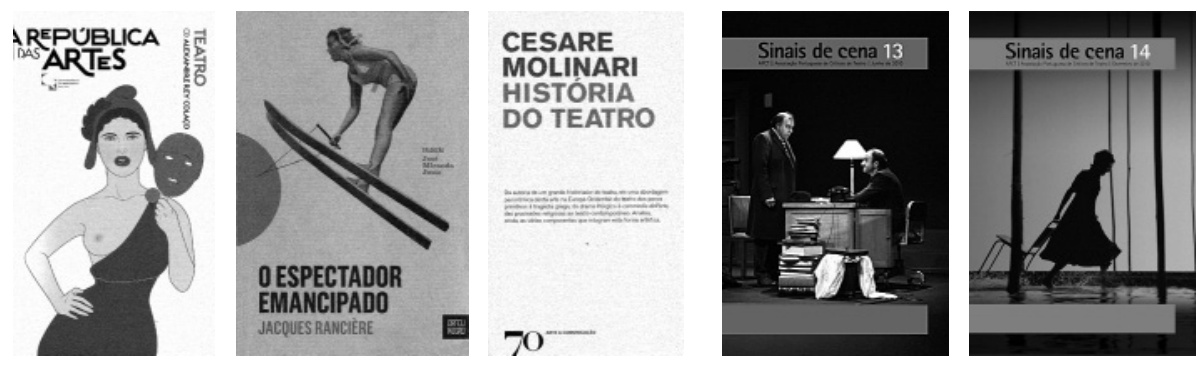

TORRADO, António, Xerazade não está só, Santarém, Artemrede, 2008. [peça original]

--, $\mathrm{O}$ mistério da cidade de Hic-Hec-Hoc, Coimbra, Calendário, 2008. [peça original]

--, 0 adorável homem das neves (Mágica em 2 actos), Lisboa, Editorial Caminho, 2008, 5a ed. [peça original em reedição]

--, O homem sem sombra, Lisboa, Editorial Caminho, 2008, 2a ed. [peça original em reedição]

--, Toca e foge ou A flauta sem mágica (em 2 actos), Lisboa, Editorial Caminho, 2008, 2a ed. [peça original em reedição]

\section{Adenda à lista publicada na Sinais de cena n. ${ }^{\circ} 9$ (2007)}

AA.W., O Altitudes e eu, s.I. [Campo Benfeito - Gosende] Teatro Regional da Serra de Montemuro, 2007. [estudos / documentos]

BARROS, Orlando Ferreira, A elegia da Madre Seca. Teatro: Tetralogia da procriação, vol. 1, Viana do Castelo, Centro Cultural do Alto Minho, Cronos Teatro, 2007. [peça original]

--, A simetria do útero. Teatro: Tetralogia da procriação, vol. 2, Viana do Castelo, Centro Cultural do Alto Minho, Cronos Teatro, 2007. [peça original]

--, A remuneração das fêmeas. Teatro: Tetralogia da procriação, vol. 3, Viana do Castelo, Centro Cultural do Alto Minho, Cronos Teatro, 2007. [peça original]

_- A estuporação de Maria. Teatro: Tetralogia da procriação, vol. 4, Viana do Castelo, Centro Cultural do Alto Minho, Cronos Teatro, 2007. [peça original]

CASTRO, Jorge, Auto das danações: Versalhada em um acto, que o tempo não está para desperdícios que não atem nem desatem, Lisboa, Apenas Livros, Teatro no Cordel n. ${ }^{\circ}$, 2007. [peça original]

FERREIRA, Raquel / FERREIRA, Maria / SILVA, Mariana / SOVERAL, Teresa / VIEIRA, Cristina, O Barba azul: Ken Kills the Barbies, Lisboa, Apenas Livros, Teatro no Cordel n. ${ }^{\circ}$, 2007. [peça original]

LEIRADELLA, Cunha de, 0 homem calado. Comédia de absurdo, Lisboa, Apenas Livros, Teatro de Cordel, n. ${ }^{\circ}$ 7, 2007. [peça original]

TORRADO, António, Era uma vez quatro, Lisboa, Editorial Caminho, 2007. [peça original]
Adenda à lista publicada na Sinais de cena n. $^{\circ} 7$ (2006)

BECKETT, Samuel, À espera de Godot. Uma tragicomédia em dois actos, trad. José Maria Vieira Mendes, Lisboa Livros Cotovia, Teatro, 2006, 3a ed. [tradução em reedição]

GUEDES, Maria Estela, Ofício da trevas, Lisboa, Apenas Livros, Teatro no Cordel n. 2 2, 2006. [peça original]

--, A Boba: Monólogo em três insónias e um despertador pref. Eugénia Vasques, Lisboa, Apenas Livros, Teatro no Cordel n. ${ }^{\circ} 4,2006$. [peça original]

LELLO, Rita, A princesa do amor de sal, Lisboa, Apenas Livros, Teatro no Cordel n. 3 , 2006. [peça original]

TORRADO, António, Salta para o saco, Porto, Civilização, 2006. [peça original]

\section{Adenda à lista publicada na Sinais de cena $\mathrm{n}^{\circ} 3$ (2004)}

ARISTÓFANES, Os cavaleiros, tradução, introdução e notas de Maria de Fátima Sousa e Silva, Lisboa, Edições 70, Clássicos Gregos e Latinos, 2004. [tradução]

LOPES, Teresa Rita, As barbas de sua Senhoria. Peça para marionetas (ou actores que as imitem), Lisboa, Apenas Livros, Teatro no Cordel, n. ${ }^{0} 1,2004,2^{\mathrm{a}}$ e $3^{\mathrm{a}}$ ed. [peça original em reedição]

MEDINA, Vitor, Sociedade de Instrução Tavaredense. Cem anos: 1904-2004 ao serviço do povo... e caminhando coord. José Augusto Cardoso Bernardes, s.l. [Figueira da Foz], s.e. [Sociedade de Instrução Tavaredense], 2004. [estudos / documentos]

\section{Adenda à lista publicada na \\ Sinais de cena $n .^{\circ} 1$ (2003)}

LOPES, Teresa Rita, As barbas de sua Senhoria. Peça para marionetas (ou actores que as imitem), Lisboa, Apenas Livros, Teatro no Cordel n. ${ }^{\circ}$, 2003. [peça original]

TORRADO, António, Doze de Inglaterra seguido de O guardavento (2 peças em 1 acto), Lisboa, Editorial Caminho, 2003, 2 ${ }^{\mathrm{a}}$ ed. [peça original em reedição] 